\title{
Knowledge, Attitude, and Practice towards Labor Pain Management and Associated Factors among Skilled Birth Attendants Working at Hospitals Found in Central, West, and North Gondar Zones, Northwest Ethiopia, 2019: A Multicenter Cross-Sectional Study
}

\author{
Eyasu Tekile Solomon, ${ }^{1}$ Fisseha Yetwale Kassie $\mathbb{D}^{2},{ }^{2}$ Dawit Gebeyehu Mekonnen, ${ }^{3}$ \\ Muhabaw Shumye Mihret $\mathbb{D}^{3},{ }^{3}$ Addisu Taye Abate, ${ }^{4}$ and Amanuel Addisu Dessie $\mathbb{D}^{5}$ \\ ${ }^{1}$ Amhara Regional Health Bureau, Amhara National Regional State, Bahir Dar, Ethiopia \\ ${ }^{2}$ Department of General Midwifery, School of Midwifery, College of Medicine and Health Sciences, University of Gondar, \\ Gondar, Ethiopia \\ ${ }^{3}$ Department of Clinical Midwifery, School of Midwifery, College of Medicine and Health Sciences, University of Gondar, \\ Gondar, Ethiopia \\ ${ }^{4}$ School of Nursing, College of Medicine and Health Sciences, University of Gondar, Gondar, Ethiopia \\ ${ }^{5}$ Department of Public Health, College of Health Sciences, Woldia University, Woldia, Ethiopia
}

Correspondence should be addressed to Fisseha Yetwale Kassie; fissehayetwale99@gmail.com

Received 24 September 2020; Revised 14 April 2021; Accepted 7 May 2021; Published 15 May 2021

Academic Editor: Federica Galli

Copyright ( 2021 Eyasu Tekile Solomon et al. This is an open access article distributed under the Creative Commons Attribution License, which permits unrestricted use, distribution, and reproduction in any medium, provided the original work is properly cited.

\begin{abstract}
Introduction. Delivery of the infant into the arms of a conscious and pain-free mother is the most exciting and rewarding moment in maternal care services. Physical and mental care of women during delivery requires good knowledge and a positive insight to the needs and rights of the mothers. Little was known regarding skilled birth attendants' knowledge, attitude, and practice towards labor pain management in the study area. Hence, the current study aimed at assessing knowledge, attitude, and practice, and associated factors towards labor pain management among skilled birth attendants working at hospitals found in central, west, and north Gondar zones, northwest Ethiopia, 2019. Method. A multicenter institution-based cross-sectional study was conducted from June 1 to 30 , 2019. A census sampling technique was used to include a total of 336 skill birth attendants. A pretested standardized self-administered questionnaire was used to collect the data. The data were then entered into Epi Info 7.1.2 and exported to SPSS version 25 for analysis. Multivariable logistic regression analyses were undertaken to identify factors associated with outcome variables. The level of significance of the study was declared based on adjusted odds ratio with $95 \%$ confidence interval at a $p$ value of $\leq 0.05$. Result. The proportion of skill birth attendants having good knowledge, a favorable attitude, and a good practice on labor pain relief methods was $47 \%, 41.96 \%$, and $57.14 \%$, respectively. Age of $\leq 30$ years ( $A O R=5.43 ; 95 \%$ CI: $1.25,23.53$ ), educational status of $2^{\text {nd }}$ degree and above $(\mathrm{AOR}=3.56 ; 95 \% \mathrm{CI}: 1.32,9.60)$, working at a private primary hospital (AOR: $=6.55 ; 95 \% \mathrm{CI}: 2.15,19.93)$, and working at a referral hospital $(\mathrm{AOR}=2.24: 95 \% \mathrm{CI}: 1.01,4.93)$ are factors significantly associated with good knowledge while having good knowledge on labor pain relief methods ( $\mathrm{AOR}=2.26 ; 95 \% \mathrm{CI}: 1.42,3.60)$ and working at private primary hospitals (AOR $=7.01 ; 95 \% \mathrm{CI}: 1.92,25.65)$ had statistically significant association with favorable attitude and good practice on labor pain relief methods, respectively. Conclusion and Recommendations. Poor knowledge, unfavorable attitude, and poor practice towards labor pain management were found in this study. Strengthening the capacity of public health facilities and providing continuous professional development (CPD) training for the skilled birth attendants would be helpful in improving knowledge, attitude, and practice towards labor pain management.
\end{abstract}




\section{Introduction}

For almost all women, labor involves pain which is often described as the most severe pain that a woman ever has to face, and it is caused by uterine contractions, associated with dilation of the cervix and stretching of the lower uterine segment [1]. Pain management during child birth is the treatment or prevention of pain that a woman may experience during labor and delivery, by using pharmacological options, oral tablets, inhalation analgesia, intravenous or intramuscular opioids and regional analgesia and/or nonpharmacological options including continuous support of a companion, directed breathing and relaxation techniques, massage, laboring in water, and the use of transcutaneous electrical nerve stimulation in early labor $[2,3]$.

Ensuring births assisted by skilled birth attendants (SBAs) is a crucial approach in reducing maternal and newborn morbidity and mortality [4]. However, evidence suggests that there is a high disparity in proportion of laboring mothers attended by SBAs across sociodemographic status of the women. For example, approximately $72 \%$ of births among rural mothers were attended by SBAs while that of among urban resident mothers was about $90 \%$ globally in 2019 [4]. In Ethiopia, about $80 \%$ and $21 \%$ of the births were attended by skilled birth attendants in urban and rural-based health facilities, respectively [4].

One of the most exciting and rewarding moments for all SBAs is assisting the birth of an infant with a pain-free mother [5, 6]. The American College of Obstetricians and Gynecologists (ACOG) describes that there is no other circumstance where it is considered as acceptable for a laboring mother to experience untreated severe pain during the event of giving birth, while under a physician's care [7]. Thus, pain relief in labor is one of the basic competencies of SBAs and considered as an essential part of intrapartum care. In this context, all women have the need to receive a range of various pain relief options for labor and delivery. In addition, providing good pain relief options during labor could be a critical incentive to increase healthcare facility deliveries since it motivates and encourages mothers to have facility-based deliveries rather than home-based deliveries by traditional birth attendants, and in turn may ultimately decrease the prevalence of labor and delivery related maternal morbidities and mortalities. Despite this fact, many of the laboring women suffer from unmanaged labor pain that can be subsided through quality and compassionate pain management [3] and the worst scenario in this regard happens in developing countries including Ethiopia where most women still go through a painful labor $[5,6]$.

Ethiopian government has strived to enhance provision of physical, psychological, and pharmacological methods of labor pain relief methods and put it as core competencies under practice standard III of Ethiopian Federal Ministry of Health (EFMoH) [8]. However, provision of both pharmacologic and nonpharmacologic pain relief options for labor remains infrequent $[3,9]$. This may be as a result of several factors, including lack of awareness, healthcare delivery systems, misunderstanding regarding acceptability, and safety and availability of pain relief options. In this perspective, growing the knowledge and attitude of SBAs towards labor pain management is paramount $[10,11]$.

Therefore, evidence in this regard is compulsory. However, there was scarce of shreds of evidence about the knowledge, attitude, and practice and predictors regarding labor pain management among SBAs working in Ethiopia. This study, therefore, aimed at assessing knowledge, attitude, and practice on labor pain management and associated factors among SBAs working at hospitals found in central, west, and north Gondar zones, northwest Ethiopia, 2019.

We hypothesize the following:

(1) Skilled birth attendants' knowledge of labor pain management (LPM) can be significantly associated with their sociodemographic characteristics, education-related factors, and institution-related factors such as type of hospital.

(2) Skilled birth attendants' attitudes towards LPM can be influenced by their sociodemographic characteristics, education-related factors, knowledge on LPM, and institution-related factors such as type of a hospital.

(3) The level of LPM practice by SBAs can be affected by various factors such as the practitioners' sociodemographic characteristics, education-related factors, knowledge status on LPM, attitude towards LPM, and institution-related factors such as the type of hospital.

\section{Methods}

2.1. Study Design, Period, and Settings. An institution-based cross-sectional study was conducted from June $1^{\text {st }}$ to $30^{\text {th }}$, 2019. The study was conducted in all hospitals found in central, west, and north Gondar zones which are located in the Amhara National Region of Ethiopia. In the three zones, there are a total of 14 hospitals including 11 primary public hospitals, one specialized public hospital, and 2 private hospitals which provide services for over 7 million people from the surrounding area. In all hospitals, labor and delivery services are provided.

2.2. Source and Study Population. All SBAs working at hospitals found in the central, west, and north Gondar zones were the source population while those SBAs who were working at labor and delivery wards of the hospitals during the study period were the study population.

2.3. Inclusion and Exclusion Criteria. All permanently employed SBAs who were working at labor and delivery wards of the hospitals during the study period were included in the study, whereas those SBAs who were not available (i.e., who were on annual leave, maternity leave, or seriously ill) during the time of data collection were excluded from the study.

2.4. Sample Size Determination, Sampling Technique, and Procedures. The sample size was estimated by using single population proportion formula with the following 
assumptions: proportion of SBAs having good knowledge, favorable attitude, and good practice on LPM $-60.1 \%, 56.7 \%$, and $43.3 \%$, respectively, based on a study done in northern Ethiopia [12], level of confidence 95\%, margin of error 5\%, and nonresponse rate $10 \%$. Thus, the sample size $(n)$ was calculated as follows: $n=\left[\left(\begin{array}{ll}Z & \alpha / 2\end{array}\right)^{2} * P(q)\right] / d^{2}$; where $n=$ sample size $, Z \alpha / 2=1.96, d=$ margin of error $(5 \%)$, $p=$ prevalence in previous study $(P=60.1 \%=0.601$ for knowledge, $p=56.7 \%=0.567$ for attitude and $P=43.3 \%=$ 0.433 for practice), $q=1-P$ (i.e., $q=0.399$ for knowledge, 0.433 for attitude, and 0.567 for practice). Accordingly, the sample size $(n)=\left[(1.96)^{2 *} 0.601 *(1-0.601)\right] /(0.05)^{2}=369$ for knowledge, $\left[(1.96)^{2} * 0.567 *(1-0.567)\right] /(0.05)^{2}=378$ for attitude and $\left[(1.96)^{2} * 0.433 *(1-0.433)\right] /(0.05) 2=378$ for practice. After taking the largest one (i.e., $n=378$ ) and adding $10 \%$ nonresponse rate, the final total sample size becomes 417 . However, since the actual number of the study population was less than the calculated sample size, all (363) SBAs were included in the study by using census sampling method.

2.5. Study Variables. The dependent variables of this study include knowledge on LPM, attitude towards LPM, and practice towards LPM, whereas the explanatory variables include sociodemographic factors (such as age, sex, religion, monthly income, and marital status), education-related factors (like level of education, profession, years of experience, and in-service training on labor pain management), and institution-related factors (health institution policy, number of SBAs, and availability of equipment and analgesic drugs).

\subsection{Operational and Term definitions}

Skilled birth attendant: an accredited health professional such as a midwife, doctor, health officer, or nurse who has been educated and trained to proficiency in the skill needed to manage normal pregnancies, childbirth, and the immediate postnatal period, and in identification, management, and referral of complications in women and newborns

Good knowledge: those who scored mean value and above on knowledge-related LPM questions

Favorable (positive) attitude: those who scored mean value and above on attitude-related LPM questions

Good practice: those who scored mean value of and above on practice-related LPM $t$ questions

2.7. Data Collection Methods, Tools, and Procedures. The source of data for this study was based on the self-report of respondents with no objective measures (like observation) to evaluate them. Data were collected by using a pretested and structured self-administered questionnaire. The questionnaire has four parts: the first section of the questionnaire contains $s$ sociodemographic factors (such as age, sex, religion, and marital status), education-related factors (such as level of education, profession, and professional experience), and institution-related factors (such as health institution policy, availability of equipment, and analgesic drugs). The second section contains knowledge-related questions. The third section has attitude-related questions and the fourth section comprises practice-related questions (Additional file 1). The tool was adopted from a previous related study [13]. A total of seven midwives with diploma level of education were employed as data collectors and 3 BSc midwives who had an experience of data collection were employed as supervisors. After the study purpose was briefly presented and informed consent was taken from each study participant, the data collectors distributed the questionnaire and collected the data.

2.8. Data Quality Control. The quality of data was ensured by proper designing and pretesting of the questionnaire at Adiss Zemen and Debre Tabor Hospitals on 42 SBAs prior to the actual data collection to ensure quality, clarity, and understandability of the questionnaire. Based on the pretest feedback, some questions were rephrased and the final questionnaire was prepared. Training was given to the data collectors and supervisors for one full day regarding the questionnaire (on the objective of the study, how to approach the study participants, and how to administer and collect the questionnaires timely). The respondents were given brief orientation before they started to fill the questionnaire. Every day after the data collection, filled questionnaires were reviewed and checked for completeness and relevance by the supervisors and the principal investigator. For controlling errors during data analysis, frequency check was done for each variable.

2.9. Data Processing and Analysis. All the questionnaires had been checked visually and coded and the data were entered into EPI Info version 7 and then exported to SPSS Version 22 for analysis. Data analysis was carried out using SPSS version 22 software. Descriptive statistics such as frequencies mean and median with standard deviation had been calculated and illustrated by using tables, graphs, and charts. Binary logistic regression was run to see the crude significant relation of each independent variable with the dependent variables. Variables with $p$ value less than or equal to 0.20 were fitted into multivariable logistic regressions for controlling the possible effect of confounders, and finally the variables which had independent association with LPM were identified on the basis of AOR, with $95 \% \mathrm{CI}$ and $p$ value less than 0.05 .

\section{Results}

3.1. Sociodemographic Characteristics of the Respondents. From the total of 363 study participants required for the study, only 336 participated and filled the questionnaire, giving a total response rate of $92.56 \%$. The mean age of the participants was 27.6, and the minimum age recorded was 22 years, while 38 years was the maximum age. More than half (58\%) of the participants were males and the majority (64\%) of the respondents were Orthodox Tewahido religion 
followers. Looking at the profession of the participants, more than half $(56 \%)$ of them were midwives A significant difference was observed on the level of education of the participants and on their working institution, where almost $90 \%$ of them were first-degree holders and just above $82 \%$ of the respondents were working in public primary hospitals. Almost all (98.5\%) of the participants had confessed that at least one labor analgesia was available in their working institution (Table 1).

3.2. Knowledge about LPM. The proportion of SBAs having good knowledge on LPRMs was $47.02 \%$ (95\% CI: $41.4 \%$, $52.4 \%)$.

Moreover, 60 (17.9\%) of the respondents had reported that they knew only pharmacological LPRMs while 50 $(14.9 \%)$ of the participants had reported that they knew only nonpharmacological methods and $225(67.0 \%)$ of the respondents reported that they knew both methods. Among pharmacologic methods known by the study participants, about 238 (70.8\%) knew steroidal drugs, 145 (43.2\%) knew systemic opioids, 77 (22.9\%) knew epidural analgesia, and 20 (6\%) knew inhalational methods, respectively.

Among the nonpharmacologic LPRMs mentioned by the respondents, providing psychotherapy, allowing the mother to ambulate, massaging the back, allowing free vertical positioning, and showing the woman how to bear down had accounted for the majority of the respondents' response (Table 2).

3.3. Attitude of SBAs towards LPM. About 141 (41.96\%) of the SBAs had a favorable attitude towards LPM (95\% CI: $36.9 \%, 47.9 \%)$.

3.4. Practice of LPM. This study relieved that 192 (57.14\%) of the study participants had a good practice of LPM (95\% CI: $51.8,62.2)$.

In this study, in the past one month prior to the data collection, about $14.34 \%$ of the respondents had confessed that they provided at least one of the pharmacological LPRMs, $20.72 \%$ of the respondents confessed that they provided at least one of the nonpharmacological methods, and the majority (64.94\%) of them reported that they provided at least one in both of the methods.

Among the pharmacological LPRMs, pethidine (48.37\%), paracetamol (31.37\%), and diclofenac (20.26\%) were provided by the respondents in the last one month prior to the data collection period. Concerning the nonpharmacological LPRMs provision in the preceding one month prior to the data collection period; about $23 \%$, $20.16 \%, 18.39 \%, 17.98 \%$, and $17.03 \%$ of the SBAs showed the woman how to bear down, massaged the woman's back, allowed mothers to ambulate, gave mothers psychotherapy, and allowed free vertical positioning, respectively.

3.5. Factors Associated with Knowledge of SBA on LPM. Sex, age, level of education, type of hospital, and training on LPM were the factors associated with good knowledge of
SBAs on LPM in the bivariate logistic regression analysis at $p$ value of $\leq 0.2$. On the multivariable logistic regression analysis, age, level of education, and type of hospital were found to have an independent association with knowledge of SBAs about LPM at a $p$ value of $<0.05$.

SBAs $\geq 31$ years old were 5.43 times more likely to have good knowledge about LPM than those $\leq 30$ years old ( $\mathrm{AOR}=5.43 ; 95 \% \mathrm{CI}: 1.25,23.53$ ). SBAs with educational level of second degree and above were 3.56 times more likely to have good knowledge on LPM than those with first degree and below level of education $(\mathrm{AOR}=3.56$; $95 \% \mathrm{CI}: 1.32$, 9.60). Compared to those SBAs who were working at public primary hospitals, those who were working at private primary hospitals were 6.55 times more likely to have good knowledge on LPM (AOR $=6.55$; 95\% CI: 2.15, 19.93). Similarly, those who were working at public referral hospitals were 2.24 time more likely to have good knowledge on LPM than those working at public primary hospitals $(\mathrm{AOR}=2.24 ; 95 \% \mathrm{CI}: 1.01,4.93)$ Table (3).

3.6. Factors Associated with Attitude of SBAs towards LPM. On bivariate logistic regression analysis, working institution and status of knowledge on LPM were variables associated with attitude of SBAs towards LPM at a $p$ value of $\leq 0.2$.

On the multivariable logistic regression analysis, only status of knowledge on LPM showed an independent association with attitude of SBA towards LPM at a $p$ value $<$ 0.05 . Thus, SBAs with a good status of knowledge on LPM were 2.26 times more likely to have a good attitude towards LPM than their counterparts $(\mathrm{AOR}=2.26$; $95 \% \mathrm{CI}: 1.42$, 3.60) (Table 4).

3.7. Factors Associated with SBAs' Practice of LPM. Educational status, monthly salary, type of hospital, and knowledge on LPRMs were the factors associated with SBAs' practice of LPM on the bivariate logistic regression analysis at a $p$ value of $\leq 0.2$. On a multivariable logistic regression analysis, type of hospital is the only factor which has an independent association with SBAs' practice on LPM at a $p$ value of $<0.05$. Accordingly, SBAs working at private primary hospitals were about 7 times more likely to practice LPM as compared to those SBAs who were working at public primary hospitals $(\mathrm{AOR}=7.01 ; 95 \%$ CI: 1.92, 25.65) (Table 5).

\section{Discussion}

In the current study, about $47.02 \%$ of the SBAs had good knowledge on LPM. This result is lower than what was reported in a study conducted in India (87\%) [14]. This could be attributable to the difference in the study population, where only obstetricians were included in the study conducted in India. The finding was also lower than a magnitude from a cross-sectional study conducted in three public hospitals found in rural and urban areas of Ethiopia (79\%) [15]. This discrepancy could be due to a difference in the tool used to assess knowledge status, where they assessed knowledge using a single indicator. Similarly, another cross- 
TABLE 1: Sociodemographic characteristics of SBAs working at hospitals in Gondar zones, northwest Ethiopia, 2019.

\begin{tabular}{|c|c|c|}
\hline Variables & & Frequency (\%) \\
\hline Sex & $\begin{array}{l}\text { Male } \\
\text { Female }\end{array}$ & $\begin{array}{c}195(58.0 \%) \\
141(42.0 \%)\end{array}$ \\
\hline Age (years) & $\begin{array}{l}\leq 30 \\
\geq 31\end{array}$ & $\begin{array}{c}321(95.5 \%) \\
15(4.5 \%)\end{array}$ \\
\hline Religion & $\begin{array}{l}\text { Orthodox } \\
\text { Muslim } \\
\text { Protestant }\end{array}$ & $\begin{array}{c}215(64.0 \%) \\
84(25.0 \%) \\
37(11.0 \%) \\
\end{array}$ \\
\hline Marital status & $\begin{array}{c}\text { Never married } \\
\text { Married } \\
\text { Divorced } \\
\end{array}$ & $\begin{array}{c}159(47.3 \%) \\
171(50.9 \%) \\
6(1.8 \%) \\
\end{array}$ \\
\hline Profession & $\begin{array}{c}\text { Nurse } \\
\text { Midwifery } \\
\text { Emergency surgeon } \\
\text { General practitioner } \\
\text { Gynecologist }\end{array}$ & $\begin{array}{c}45(13.4 \%) \\
188(56.0 \%) \\
20(6.0 \%) \\
71(21.1 \%) \\
12(3.6 \%)\end{array}$ \\
\hline Level of education & $\begin{array}{c}\text { Diploma } \\
1^{\text {st }} \text { degree } \\
2^{\text {nd }} \text { degree and above }\end{array}$ & $\begin{array}{c}4(1.2 \%) \\
302(89.9 \%) \\
30(8.9 \%) \\
\end{array}$ \\
\hline Monthly salary (per birr) & $\begin{array}{c}3553-7000 \\
7001-10000 \\
>10000\end{array}$ & $\begin{array}{c}234(69.6 \%) \\
61(18.2 \%) \\
41(12.2 \%)\end{array}$ \\
\hline Working institution & $\begin{array}{l}\text { Public primary hospital } \\
\text { Private primary hospital } \\
\text { Referral hospital }\end{array}$ & $\begin{array}{c}276(82.1 \%) \\
24(7.1 \%) \\
36(10.7 \%)\end{array}$ \\
\hline Availability of at least one labor analgesia drug & $\begin{array}{l}\text { Yes } \\
\text { No }\end{array}$ & $\begin{array}{c}331(98.5 \%) \\
5(1.5 \%)\end{array}$ \\
\hline
\end{tabular}

TABLE 2: Knowledge of SBAs on nonpharmacologic labor pain relief methods who are working at hospitals found in Gondar zones, northwest Ethiopia, 2019.

\begin{tabular}{|c|c|c|}
\hline Variables & & Frequency (\%) \\
\hline \multirow{2}{*}{ Psychotherapy } & Yes & $183(54.5 \%)$ \\
\hline & No & $153(45.5 \%)$ \\
\hline \multirow{2}{*}{ Allow the mother to ambulate } & Yes & $163(48.5 \%)$ \\
\hline & No & $173(51.5 \%)$ \\
\hline \multirow{2}{*}{ Massage the back } & Yes & $148(44.0 \%)$ \\
\hline & No & $188(56.0 \%)$ \\
\hline \multirow{2}{*}{ Allow free vertical positioning } & Yes & $113(33.6 \%)$ \\
\hline & No & $223(66.4 \%)$ \\
\hline \multirow{2}{*}{ Transcutaneous electrical nerve stimulation } & Yes & $62(18.5 \%)$ \\
\hline & No & $274(81.5 \%)$ \\
\hline \multirow{2}{*}{ Show the woman how to bear down } & Yes & $109(32.4 \%)$ \\
\hline & No & $227(67.6 \%)$ \\
\hline \multirow{2}{*}{ Acupuncture } & Yes & $11(3.3 \%)$ \\
\hline & No & $325(96.7 \%)$ \\
\hline \multirow{2}{*}{ Hypnosis } & Yes & $30(8.9 \%)$ \\
\hline & No & $306(91.1 \%)$ \\
\hline \multirow{2}{*}{ Allow companion of laboring woman of choice } & Yes & $9(2.7 \%)$ \\
\hline & No & $327(97.3 \%)$ \\
\hline \multirow{2}{*}{ Music therapy } & Yes & $3(0.9 \%)$ \\
\hline & No & $333(99.1 \%)$ \\
\hline
\end{tabular}


TABLE 3: Factors associated with knowledge on LPM among SBAs working at hospitals in Gondar zones, northwest Ethiopia, 2019.

\begin{tabular}{|c|c|c|c|c|c|}
\hline \multirow{2}{*}{\multicolumn{2}{|c|}{ Variables }} & \multicolumn{2}{|c|}{ Knowledge on LPM } & \multirow{2}{*}{ COR $(95 \% \mathrm{CI})$} & \multirow{2}{*}{ AOR $(95 \% \mathrm{CI})$} \\
\hline & & Good & Poor & & \\
\hline \multirow{2}{*}{ Sex } & Male & 102 & 93 & $1.67(1.07-2.58)$ & \\
\hline & Female & 56 & 85 & 1 & \\
\hline \multirow{2}{*}{ Age } & $\leq 30$ & 155 & 166 & $3.74(1.03-13.49)$ & $5.43(1.25-23.53)^{*}$ \\
\hline & $\geq 31$ & 3 & 12 & 1 & \\
\hline \multirow{2}{*}{ Educational status } & $\leq 1^{\text {st }}$ degree & 137 & 169 & 1 & \\
\hline & $\geq 2^{\text {nd }}$ degree & 21 & 9 & $2.88(1.28-6.49)$ & $3.56(1.32-9.60)^{*}$ \\
\hline \multirow{3}{*}{ Hospital type } & Public primary & 113 & 163 & 1 & \\
\hline & Private primary & 20 & 4 & $7.21(2.4-21.67)$ & $6.55(2.15-19.93)^{*}$ \\
\hline & Referral & 25 & 11 & $3.28(1.55-6.93)$ & $2.24(1.01-4.93)^{*}$ \\
\hline \multirow{2}{*}{ Got training on LPM } & Yes & 119 & 108 & $2.03(1.27-3.26)$ & \\
\hline & No & 38 & 70 & $1^{*}$ & \\
\hline
\end{tabular}

$1=$ reference category, ${ }^{*}=p$ value $<0.05$.

TABle 4: Factors associated with attitude on LPM among SBAs working at hospitals in Gondar zones, northwest Ethiopia, 2019.

\begin{tabular}{lccccc}
\hline \multirow{2}{*}{ Variables } & & \multicolumn{2}{c}{ Attitude on LPM } & COR with 95\% CI & \multirow{2}{*}{ AOR with 95\% CI } \\
& & Favorable & Unfavorable & & $1^{*}$ \\
\multirow{2}{*}{ Type of the hospital } & Public primary & 126 & 150 & $0.05(0.01-0.39)$ & $0.76(0.37,1.54)$ \\
\hline \multirow{2}{*}{ Knowledge status on LPM } & Private primary & 1 & 23 & $1.69(1.09-2.62)$ & $2.26(1.42,3.60)^{* *}$ \\
& Referral & 14 & 81 & 114 & $1^{*}$ \\
\hline
\end{tabular}

$1^{*}=$ reference category, ${ }^{* *}=p$ value $<0.05$.

TABLE 5: Factors associated with practice on LPM among SBAs working at hospitals in Gondar zones, northwest Ethiopia, 2019.

\begin{tabular}{|c|c|c|c|c|c|}
\hline \multicolumn{2}{|c|}{ Variables } & \multicolumn{2}{|c|}{$\begin{array}{c}\text { SBA's practice on } \\
\text { LPM }\end{array}$} & \multirow[t]{2}{*}{ COR $(95 \% \mathrm{CI})$} & \multirow[t]{2}{*}{ AOR (95\% CI) } \\
\hline & & Good & Poor & & \\
\hline Educational status & $\begin{array}{l}\leq 1^{\text {st }} \text { degree } \\
\geq 2^{\text {nd }} \text { degree }\end{array}$ & $\begin{array}{c}168 \\
24 \\
\end{array}$ & $\begin{array}{c}138 \\
6 \\
\end{array}$ & $\begin{array}{c}1^{*} \\
3.29(1.31-8.27) \\
\end{array}$ & \\
\hline Monthly salary (birr) & $\begin{array}{l}\leq 6055 \\
>6055\end{array}$ & $\begin{array}{c}110 \\
82\end{array}$ & $\begin{array}{c}117 \\
27\end{array}$ & $\begin{array}{c}1^{*} \\
3.23(1.95-5.36)\end{array}$ & \\
\hline Type of the hospital & $\begin{array}{c}\text { Public primary } \\
\text { Private primary } \\
\text { Referral } \\
\end{array}$ & $\begin{array}{c}147 \\
21 \\
24 \\
\end{array}$ & $\begin{array}{c}129 \\
3 \\
12 \\
\end{array}$ & $\begin{array}{c}1^{*} \\
6.14(1.79-21.07) \\
1.76(0.84-3.65) \\
\end{array}$ & $7.01(1.92,25.65)^{* *}$ \\
\hline Knowledge on LPM & $\begin{array}{l}\text { Good } \\
\text { Poor }\end{array}$ & $\begin{array}{c}103 \\
89\end{array}$ & $\begin{array}{l}55 \\
89\end{array}$ & $\begin{array}{c}1.87(1.21-2.91) \\
1^{*}\end{array}$ & \\
\hline
\end{tabular}

$1^{*}=$ reference category, ${ }^{* *}=p$ value $<0.05$.

sectional study conducted in Tigray region of northern Ethiopia shows that about $60.1 \%$ of the respondents had good knowledge, which was greater than the result of the current study [12]. This could be as a result of difference in study area, where only general hospitals were included in their study.

However, the result of this study is higher as compared to a study conducted in Saudi Arabia where $38.1 \%$ of the SBAs had good knowledge [16]. This could be attributed to difference in the study setting and area. Compared to a study conducted in Nigeria, the finding of this study was found to be greater, where $33.3 \%$ of the respondents had good knowledge on their study [17]. This discrepancy could arise due to difference in the study population where only nurses were included in their study.
Respondents aged 31 years and above were 5.43 times more likely to have good knowledge about LPM than those SBAs aged 30 years and below. This finding is consistent with a study conducted at United States of America [18]. This could be due to the association of knowledge with development and maturity level; advancing in age will increase the maturity level and responsibility of a working person. In the current study, even if the people older than 31 are only $4 \%$ of the overall participants and results regarding age and knowledge must be taken with caution, this data might highlight a gap in the education of young SBAs that must be addressed. In addition, the association could be ascribed to limitations of data collection method, self-report; the reason for this finding might be attributed to the fact that younger SBAs have a poor perception of their knowledge while older 
SBAs feel more self-confident. Therefore, further studies are recommended to be conducted by taking the aforesaid limitation into consideration. Those SBAs with educational level of second degree and above were 6.55 times more likely to have good knowledge on LPM than those with first degree and below level of education. This finding is in agreement with previous studies which showed that knowledge regarding LPM was determined by the level of education of SBAs [12,18]. This could be due to the fact that a skill in searching and acquiring for new knowledge increases as the level of education of the person increases. This implies that ensuring continuous professional development (CPD) of the SBAs would be helpful in enhancing knowledge on LPM. However, the finding needs to be interpreted cautiously as the result is generated from the data which were gathered through self-report from the SBAs and only $8.9 \%$ of the SBAs were $\geq 2^{\text {nd }}$ degree holders.

Those SBAs who were working at private primary hospitals were 6.55 times more likely to have good knowledge about LPRMs as compared to SBAs working at public primary hospitals. Similarly, those who were working at the public referral hospitals were 2.24 times more likely to have good knowledge about LPRMs than those working at public primary hospitals. This finding is consistent with findings of the studies undertaken in Saudi Arabia, Nigeria, Australia, and Belgium [16, 19-21]. This could be because of the institutional policies in private sector focusing on giving high standard of care so as to attract clients, and therefore have educated manpower.

Concerning attitude towards LPM, the current study reveals that the proportion of SBAs having a favorable attitude towards LPM is $41.96 \%$. This result is lower compared with a cross-sectional study conducted in India (87\%) [12]. This discrepancy could be attributed to the difference in the study population, where only obstetricians were included on the study conducted in India. The finding was also lower as compared to a result reported from a study in Ethiopia $(77 \%)$ and a study conducted in Nigeria $(94.8 \%)[15,20]$. This could be due to the difference in the tool to assess knowledge status where both of the previous aforementioned studies assessed knowledge using a single indicator. Similarly, another study conducted in northern Ethiopia showed that about $56.7 \%$ of the respondents had favorable attitude which was higher compared with the result of the current study [12]. This discrepancy could be due to a difference in the study area where only general hospitals were included in their study.

However, the result of the current study was higher as compared to a study conducted in Amhara Region of Ethiopia where only $26.4 \%$ of the SBAs had a favorable attitude towards LPM [22]. This could be due to a difference in the study settings and areas.

Those SBAs who had good knowledge on LPM were 2.26 times more likely to have a favorable attitude LPM towards as compared to SBAs with a poor knowledge about LPRMs. This finding is consistent with a study done in the United States of America [18]. This could be explained as an increase in knowledge and awareness about LPM will make the SBAs tend to have a good attitude towards LPM.
In this study, the proportion of SBAs having a good practice of LPM is $57.14 \%$. The finding is in line with a crosssectional study done in public hospitals of Addis Ababa, Ethiopia, where more than half $(54.2 \%)$ of the study participants had a good LPM practice [23].

However, the practice of LPM of this study was found to be greater as compared to a study conducted in Ibana, Nigeria (34.5\%) [24]. This discrepancy could be because of the difference in the study population in which only nurses and midwives were included in their study. Similarly, the finding of the current study was higher compared with a study conducted in public health facilities of Kembata Tembaro zone, Ethiopia, where only $37.9 \%$ of the respondents had a good LPM practice [25]. This discrepancy in magnitude of LPM practice could be ascribed to variation in the study settings in which health centers were also included in their study. On the contrary, the result of a current study is lower than a magnitude reported from a study done in Egypt where about $63.2 \%$ of the study participants had a good LPM practice [13]. The discrepancy could arise from a difference between the study areas.

Those SBAs who were working at private primary hospitals were about 7 times more likely to practice LPM as compared to those SBAs working at public primary hospitals This finding is consistent with findings of two cross-sectional studies conducted in Ethiopia [23,25]. The association could be because of the institutional policies in the private sectors which focus on giving high standard of care so as to attract clients, and therefore have better trained manpower to provide LPM.

Finally, the authors would like to advise the readers to interpret the findings of this study with caution as it has certain limitations. The reports of this study might be overestimated as the source of data for this study was based on the self-report of respondents which is prone to recall bias. However, with all those limitations, we strongly believe that this study is helpful to the scientific community as it was conducted in the settings where there was limited evidence. Thus, it will provide a baseline insight for researches, thereby inspiring future researches in this theme.

\section{Conclusion}

In this study, the proportion of SBAs having good knowledge, a favorable attitude, and a good practice of LPM was lower than the results of many of the previous studies. Strengthening the capacity of the public health facilities and assuring continuous professional development (CPD) through trainings specific to LPM would be helpful in improving LPM practices.
Abbreviations
AOR: $\quad$ Adjusted odds ratio
COR: Crude odds ratio
CI: Confidence interval
EFMOH: Ethiopian Federal Ministry of Health
EPI Statistical Package for Epidemiological
INFO: Information Analysis 
ETB: $\quad$ Ethiopian birr

KAP: Knowledge, attitude, and practice

LPM: $\quad$ Labor pain management

LPRMs: Labor pain relief methods

SBAs: $\quad$ Skilled birth attendants

SD: $\quad$ Standard deviation

SPSS: $\quad$ Statistical Package for Social Sciences.

\section{Data Availability}

The authors declare that the data regarding this manuscript can be accessed as per the request of any interested body and can be accessed by emailing the corresponding author using on fissehayetwale99@gmail.com.

\section{Ethical Approval}

Ethical clearance was obtained from the Ethical Review Board (IRB) of University of Gondar, College of Medicine and Health Sciences, School of Midwifery. Formal letter of cooperation was written from the School of Midwifery to the respective hospitals, and permission was obtained accordingly.

\section{Consent}

Informed written consent was obtained from each study participant, and each respondent was informed about the objective of the study. Any participant who was not willing to participate in the study was not forced to participate. Privacy and confidentiality of the study participants were maintained.

\section{Disclosure}

The granting agency did not have a role in the design, collection, analysis, and interpretation of data or in writing the manuscript.

\section{Conflicts of Interest}

The authors declare that they have no competing interests.

\section{Authors' Contributions}

ETS, FYK, and DGM contributed to conception and design, acquisition of data, analysis and interpretation of data, critical revision of the manuscript, and final approval of the version to be published. MSM, ATA, and AAD contributed to interpretation of the data, drafting of the manuscript, critical revision of the manuscript, and final approval of the version to be published. All authors read and approved the final version of the manuscript to be submitted for publication.

\section{Acknowledgments}

The authors would like to thank the study participants for their volunteer participation and time. Their heartfelt thanks also go to Amhara Regional Health Bureau, respected hospitals, and data collectors for their contribution to accomplish this work. The authors would also like to acknowledge the University of Gondar, College of Medicine and Health Sciences, School of Midwifery, for providing ethical clearance. The research was supported by a grant from Amhara National Regional Health Bureau.

\section{Supplementary Materials}

Additional file 1 is a questionnaire comprising questions on participants' sociodemographic characteristics; knowledge, attitude, and practice on labor pain management; reasons for not practicing labor pain management; and institutional factors which have been adapted from previous similar literature [13]. (Supplementary Materials)

\section{References}

[1] N. M. Beigi, K. Broumandfar, P. Bahadoran, and H. A Abedi, "Women's experience of pain during childbirth," Iranian Journal of Nursing and Midwifery Research, vol. 15, pp. 77-82, 2010.

[2] M. Dolatian, A. Hasanpour, and R. A. H. Heshmat, "The effect of reflexology on labour pain intensity," Journal of Zanjan University of Medical Sciences and Health Services, vol. 18, pp. 52-61, 2010.

[3] National Institute of Health and Care Excellence, Intrapartum Care: Care of Healthy Women and Their Babies during Childbirth (CG190), National Institute of Health and Care Excellence [Internet], London, UK, 2014, http://www.nice. org.uk/guidance/cg190.

[4] UNICEF, Despite Accelerated Recent Progress, Millions of Births Occur Annually without Any Assistance from a Skilled Attendant at Birth, 2016.

[5] American Society of Anesthesiologists, "Misconceptions about labour and delivery," 2014, https://www.asahq.org/lifeline/ anesthesiaTopics/misconceptionsaboutlabouranddelivery.

[6] K. L. Dehne and G. Riedner, "Sexually Transmitted Infections Among Adolescents the Need for Adequate Health Services," Reproductive Health Matters, vol. 9, 2005.

[7] American College of Obstetricians and Gynecologists, "Pain relief during labour," Obstetrics and Gynecology, vol. 104, no. 213, 2004.

[8] Federal Ministry of Health, "Standard of midwifery care practice in Ethiopia," Federal Ministry of Health, Addis Ababa, Ethiopia, 2013.

[9] C. O. Imarengiaye, "Trends in pain relief in labour: implications for obstetric analgesia service in Nigeria," Nigerian Postgraduate Medical Journal, vol. 12, pp. 193-202, 2005.

[10] O. Olayemi, C. O. Aimakhu, and E. S. Udoh, "Attitudes of patients to obstetric analgesia at the university College hospital, Ibadan, Nigeria," Journal of Obstetrics and Gynaecology, vol. 23, no. 1, pp. 38-40, 2003.

[11] O. Olayemi, C. O. Aimakhu, and A. O. Akinyemi, "The influence of westernisation on pain perception in labour among parturients at the University College Hospital, Ibadan," Journal of Obstetrics and Gynaecology, vol. 26, no. 4, pp. 29-31, 2006.

[12] E. Sahile, Y. Yemaneh, A. Alehegn, and W. Nigussie, "Practice of labour pain management methods and associated factors among skilled attendants working at general hospitals in Tigray region, north iMedPub journals practice of labour pain management methods and associated factors among skilled 
attendants wo," Health Science Journals, vol. 11, no. 4, p. 516, 2017.

[13] O. Mousa, A. A. Abdelhafez, A. R. Abdelraheim, A. M. Yousef, A. A. Ghaney, and S. El Gelany, "Perceptions and practice of labour pain-relief methods among health professionals conducting delivery in minia maternity units in Egypt," Hindawi, vol. 20186 pages, 2018.

[14] B. Taneja and K. D. C. Nath, "Clinical audit on the existing attitudes and knowledge of obstetricians regarding labour analgesia," Indian Journal of Anaesthesia, vol. 48, no. 3, pp. 185-188, 2004.

[15] M. Mccauley, C. Stewart, and B. Kebede, "A survey of healthcare providers' knowledge and attitudes regarding pain relief in labour for women in Ethiopia," BMC Pregnancy Childbirth, vol. 1-6, 2017.

[16] M. Almushait, R. A. Ghani, S. Arabia, N. H. Nursing, and S. Arabia, "Perception toward non-pharmacological strategies in relieving labour pain: an analytical descriptive study," Journal of Natural Sciences Research, vol. 4, no. 2, pp. 5-12, 2014.

[17] B. Ogonna, E. Z. E. Ojerinde, A. Onibokun, and O. M. Akpa, "Knowledge and practice of pain management among nurses in labour wards in Ibadan, Nigeria," African Journal of Midwifery and Women's Health, vol. 10, no. 3, pp. 132-137, 2016.

[18] S. J. Barrett and M. A. Stark, "Factors associated with labor support behaviors of nurses," Journal of Perinatal Education, vol. 19, no. 1, pp. 12-18, 2010.

[19] A. Steel, J. Adams, D. Sibbritt et al., "Managing the pain of labour: factors associated with the use of labour pain management for pregnant Australian women," Health Expectations, vol. 18, no. 5, pp. 1633-1644, 2013.

[20] S. B. Bature, E. Ogboli-Nwasor, S. E. Adaji, and O. S. Shittu, "Pain relief in labour: a survey of awareness, attitude, and practice of health care providers," Journal of Pain Research, Dove Press, 2011.

[21] W. Christiaens, M. Verhaeghe, and P. Bracke, "Pain acceptance and personal control in pain relief in two maternity care models: a cross-national comparison of Belgium and the Netherlands," BMC Health Services Research, vol. 10, no. 1, p. 268, 2010.

[22] A. Bitew, A. Workie, T. Seyum, and T. Demeke, "iMedPub journals utilization of obstetric analgesia in labour pain management and associated factors among obstetric care givers in Amhara regional state referral hospitals, northwest Ethiopia: a hospital based cross sectional study keywords: list of ab," Journal of Biomedical Science, vol. 5, no. 2, pp. 1-6, 2016.

[23] H. Mulugeta, "The practice of labour analgesia and its perceived barriers among health care providers working in public hospitals of Addis Ababa, Ethiopia," 2016.

[24] L. O. Lawani, J. N. Eze, O. B. Anozie, C. A. Iyoke, and N. N. Ekem, "Obstetric analgesia for vaginal birth in contemporary obstetrics: a survey of the practice of obstetricians in Nigeria," BMC Pregnancy Childbirth, vol. 14, no. 1, pp. 1-6, 2014.

[25] T. Getachew, A. Taya, and A. G. Kelbore, "Utilization of obstetric analgesia in labour pain management and associated factors among obstetric caregivers in public health facilities of Kembata Tembaro Zone, Southern Ethiopia," Journal of Pain Research, pp. 3089-3097, 2018. 